Scientia Agricola

http://dx.doi.org/10.1590/0103-9016-2015-0084

\title{
Increasing the resistance of common bean to white mold through recurrent selection
}

\author{
Monik Evelin Leite, Juliana Andrade Dias, Danuza Araujo de Souza, Filipe Couto Alves, Lucas Rezende Pinheiro, João Bosco dos \\ Santos*
}

Federal University of Lavras - Department of Biology, C.P.

3037 - 37200-000 - Lavras, MG - Brazil.

*Corresponding author<jbsantos@dbi.ufla.br>

Edited by: Antonio Augusto Franco Garcia

\begin{abstract}
White mold, caused by Sclerotinea sclerotiorum (Lib.) de Bary is one of the most important diseases of the common bean (Phaseolus vulgaris L.) worldwide. Physiological resistance and traits related to disease avoidance such as architecture contribute to field resistance. The aim of this study was to verify the efficiency of recurrent selection in physiological resistance to white mold, "Carioca" grain type and upright habit in common bean. Thirteen common bean lines with partial resistance to white mold were intercrossed by means of a circulant diallel table, and seven recurrent selection cycles were obtained. Of these cycles, progenies of the $\mathrm{S}_{0: 1}, \mathrm{~S}_{0: 2}$ and $\mathrm{S}_{0: 3}$ generations of cycles III, IV, V and VI were evaluated. The best ( 8 to 10 ) progenies of the seven cycles were also evaluated, in two experiments, one in the greenhouse and one in the field. Lattice and/or randomized block experimental designs were used. The traits evaluated were: resistance to white mold by the straw test method, growth habit and grain type. The most resistant progenies were selected based on the average score of resistance to white mold. Subsequently, they were evaluated with regard to grain type and growth habit. Recurrent selection allowed for genetic progress of about $11 \%$ per year for white mold resistance and about $15 \%$ per year for the plant architecture. There was no gain among cycles for grain type. Progeny selection and recurrent selection were efficient for obtaining progenies with a high level of resistance to white mold with "Carioca" grain type and upright habit.

Keywords: Sclerotinia sclerotiorum, Phaseolus vulgaris, genetic resistance, genetic progress
\end{abstract}

Received February 20, 2015

Accepted June 04, 2015 moderate levels of resistance, equivalent to non-adapted sources used (Carneiro et al., 2011; Carvalho et al., 2013; Gonçalves and Santos, 2010; Silva et al., 2014).

In addition to physiological resistance, traits such as early maturity and others related to plant architecture, such as upright plants and open canopy, have been reported as escape mechanisms because they are unfavorable to the proliferation of the pathogen (Ender and Kelly, 2005: Kolkman and Kelly, 2002). Escape mechanisms and physiological resistance mechanisms are quantitatively inherited and controlled by QTLs (quantitative trait loci) to both small and large effect (Miklas et al., 2013; Mkwaila et al., 2011; Soule et al., 2011; Lara et al., 2014).

The low or moderate levels of resistance of the lines and the complex inheritance of the trait, limit success in selection for resistance to white mold. Recurrent selection has been considered the most efficient method in the gradual increase in frequency of desirable alleles in breeding programs. Studies such as Lyon et al. (1987) and Terán and Singh (2010a) prove the efficiency of recurrent selection for resistance to white mold.

In light of the above, the aim of this study was to verify the efficiency of recurrent selection for physiological resistance to white mold, "Carioca" grain type and upright habit in common bean.

\section{Materials and methods}

the purpose of transferring resistance alleles of such species; however, the levels of resistance obtained are still considered low or intermediate (Miklas et al., 2006; Singh et al., 2009a, b). Although some farmers consider that the cultivars used in Brazil are susceptible, lines and cultivars have, in fact, already been identified with

\author{
Obtaining the base population and experimental \\ procedures \\ Intercrossing had been carried out at a previous \\ stage on 13 lines/cultivars with partial resistance to
}


white mold (Table 1). Line A195 is an exotic source of resistance derived from the breeding program of CIAT (International Tropical Agriculture Center) (Terán and Singh, 2008). Those from number 1 to 8 are adapted to the southern region of the state of Minas Gerais, Brazil. Those from number 9 to 12 are progenies derived from backcrosses in which the donor of resistance to white mold was the source G122 or Ex Rico 23, and the recurrent parents were the M20 or Madripérola lines. The G122 line has large and red painted grains and type I growth habit; Ex Rico 23 has small white grains and type II growth habit, and both have partial physiological resistance to white mold. M20 is a carrier of anthracnose resistance alleles $\left(\mathrm{Co}-5\right.$ and $\left.\mathrm{Co}-4^{2}\right)$, partial resistance to angular leaf spot, type II growth habit and "Carioca" grain type (beige with brown stripes) (Carvalho et al., 2013), and the Madripérola cultivar has type III growth habit, excellent "Carioca" grain and high yield.

The lines/cultivars were intercrossed in the circulant diallel, where " $k$ " parents are used for obtaining "s $=2^{\prime \prime}$ hybrid combinations for each (Rangel et al., 2008). Recurrent selection cycles zero (CO), one (CI), two (CII), three (CIII), four (CIV), five (CV) and six (CVI) were obtained. In obtaining $\mathrm{C} 0$, each parent was crossed with two others. In the $\mathrm{F}_{2}$ progeny ( $\mathrm{S}_{0}$ generation) of each cross, all the plants were inoculated and evaluated, and the most resistant to white mold were selected. Then each selected progeny was intercrossed with two others to obtain cycle I. In cycles CI, CII, CIII, CIV, CV and $C V I$, the $\mathrm{F}_{1}$ progeny ( $\mathrm{S}_{0}$ generation), now segregating, were inoculated (two stems per plant), evaluated, selected before flowering and intercrossed. This procedure allowed for a reduction in the time required for obtaining each recurrent selection cycle from only one crop season, with three cycles per year. Cycles C0, CI and CII were obtained in the previous step of the program and, providing continuity to this study, cycles III, IV, V and VI were obtained.

Table 1 - Lines and cultivars of common bean used in the intercrossing grain type, 100 grain weight and plant type.

\begin{tabular}{|c|c|c|}
\hline Cultivar/line & Grain Type/100 grain weight (g) & Plant type \\
\hline 1-RP-2 & "Carioca"/25 & $\|$ \\
\hline 2-MA-IV-18-266 & "Carioca"/23 & $\|$ \\
\hline 3-BRS - Cometa & "Carioca"/23 & $\|$ \\
\hline 4-VC-16 & "Carioca"/25 & III \\
\hline 5-Majestoso & "Carioca"/25 & III \\
\hline 6-CNFRJ10564 & Pintado/42 & 1 \\
\hline 7-ESAL 550 & Jalo/45 & III \\
\hline 8- BRS - Talismã & "Carioca"/22 & $\|$ \\
\hline $9-\mathrm{RC}_{2}-\mathrm{G} 122-67$ & "Carioca"/25 & $\|$ \\
\hline $10-\mathrm{RC}_{2}-\mathrm{G} 122-72$ & "Carioca"/23 & $\|$ \\
\hline 11-RC ${ }_{1}$-ExRico-26 & "Carioca"/23 & $\|$ \\
\hline 12-RC ${ }_{1}$-ExRico-97 & "Carioca"/20 & ॥ \\
\hline 13-A195 & Bege/54 & 1 \\
\hline
\end{tabular}

Type I cultivars are determinate and upright; type II cultivars are upright and indeterminate; type III plants are prostate and indeterminate.
Within each cycle, progenies $\mathrm{S}_{0: 1}, \mathrm{~S}_{0: 2^{\prime}} \mathrm{S}_{0: 3^{\prime}} \mathrm{S}_{0: 4}$ were obtained, thereby increasing the homozygosis level. The most resistant plants of the base population $\left(\mathrm{S}_{0}\right)$ were selected to obtain the progenies in the $S_{0: 1}$ generation; after that, the most resistant progenies were selected to obtain the $\mathrm{S}_{0: 2}, \mathrm{~S}_{0: 3}$ and the $\mathrm{S}_{0: 4}$ generations. In these generations, in addition to selection for resistance to white mold, selection was performed for grain type and growth habit. For grain type, the progenies with grains far outside the "Carioca" standard were eliminated, even if they showed greater levels of resistance. The experiments were conducted in Lavras, in all generations in the dry, winter and rainy cropping seasons.

All the experiments were subjected to the same crop practices. At sowing, the fertilization used was 300 $\mathrm{kg} \mathrm{ha}{ }^{-1}$ of the formulation 8-28-16 $\left(\mathrm{N}-\mathrm{P}_{2} \mathrm{O}_{5}-\mathrm{K}_{2} \mathrm{O}\right.$, respectively) and, in topdressing at 20 days after emergence, $150 \mathrm{~kg} \mathrm{ha}^{-1}$ of ammonium sulfate. Sprinkler irrigation was used, and the other crop treatments were those normally used for the common bean crop in the region. The breeding procedure was bulk within $\mathrm{S}_{0}$ progenies, and the experimental designs, seasons and traits evaluated are shown in Table 2 . The experiments were carried out using plots of one meter rows in the $\mathrm{S}_{0: 1}$ and $\mathrm{S}_{0: 2}$ generations, and two meter rows in the $S_{0: 3}$ and $S_{0: 4}$ generations. Fifteen seeds per linear meter were sown in hills spaced at 0.2 meter, and 0.5 meter between lines.

Experiment with the better progenies for each cycle Experiments with the better progenies of the seven cycles were also performed in the field and in a greenhouse (Table 2). From these experiments, ten of the better progenies of the CIV, CV and CVI, eight of the CI, CII and $\mathrm{CIII}$ and seven progenies of the $\mathrm{C} 0$ cycles were evaluated.

In the greenhouse experiment, eight common bean seeds from the progenies selected in each cycle were sown in 3.5 liter plastic pots, containing a mixture of soil:sand:cattle manure $(3: 1: 1)$. The plants were irrigated periodically and fertilized according to crop recommendations, maintaining moisture of around $80 \%$ of the pot capacity. After emergence, five common bean plants were maintained in each pot becoming the experimental plot. In the field experiment, the crop practices were the same as those performed in the experiments with progenies of the $\mathrm{S}_{0: 3}$ generation.

\section{Evaluation of resistance to white mold, growth habit and grain type}

Inoculations were performed with the mycelium of the pathogen 28 days after emergence using the straw test method (Terán et al., 2006). All the $\mathrm{F}_{1}$ plants $\left(\mathrm{S}_{0}\right)$ of cycles CIII, CIV, CV and CVI (around 1300 per cycle) were inoculated in two main branches. In $\mathrm{S}_{0: 1,}, \mathrm{~S}_{0: 2}, \mathrm{~S}_{0: 3}$ and $S_{0: 4}$ progenies from each cycle, only one main branch was inoculated per plant in every ten plants in the plot. In the experiment with all the cycles in the greenhouse, around five plants per plot in two main branches of each plant were inoculated. In the inoculations, the most ag- 
Table 2 - Experimental design used, season and traits evaluated in each one of the generations of the four recurrent selection cycles (CIII, CIV, CV and CVI), and of the experiments with all the common bean cycles in the field and greenhouse (GH).

\begin{tabular}{|c|c|c|c|c|}
\hline Cycle & Generation & Experimental design & Sowing season & Traits evaluated \\
\hline $\mathrm{Clll}$ & $S_{0: 1}$ & Simple lattice $11 \times 11$ & dry 2011 & resistance/growth habit/grain type \\
\hline CIII & $\mathrm{S}_{0: 2}$ & Triple lattice $7 \times 7$ & rainy $2011 / 2012$ & resistance/growth habit/grain type \\
\hline CIII & $\mathrm{S}_{0: 3}$ & Triple lattice $5 \times 5$ & dry 2012 & resistance/growth habit/grain type \\
\hline CIV & $\mathrm{S}_{0: 1}$ & Simple lattice $14 \times 14$ & rainy $2011 / 2012$ & resistance/growth habit/grain type \\
\hline CIV & $\mathrm{S}_{0: 2}$ & Triple lattice $10 \times 10$ & dry 2012 & resistance/growth habit/grain type \\
\hline CIV & $\mathrm{S}_{0: 3}$ & Triple lattice $7 \times 7$ & winter 2012 & resistance/growth habit/grain type \\
\hline CV & $\mathrm{S}_{0: 1}$ & Triple lattice $15 \times 15$ & dry 2012 & resistance/growth habit/grain type \\
\hline CV & $S_{0: 2}$ & Triple lattice $10 \times 10$ & winter 2012 & resistance/growth habit/grain type \\
\hline CV & $\mathrm{S}_{0: 3}$ & Triple lattice $7 \times 7$ & rainy 2012/2013 & resistance/growth habit/grain type \\
\hline CVI & $\mathrm{S}_{0: 1}$ & Triple lattice $15 \times 15$ & winter 2012 & resistance/growth habit/grain type \\
\hline CVI & $\mathrm{S}_{0: 2}$ & Triple lattice $9 \times 9$ & rainy 2012/2013 & resistance/growth habit/grain type \\
\hline CVI & $\mathrm{S}_{0: 3}$ & Triple lattice $7 \times 7$ & dry 2013 & resistance/growth habit/grain type \\
\hline $\mathrm{CO}-\mathrm{CVI}$ & $\mathrm{S}_{0: 4}$ & $\mathrm{CBD}^{1}-192$ plots & Field-dry 2013 & resistance/growth habit/grain type \\
\hline $\mathrm{CO}-\mathrm{CVI}$ & $\mathrm{S}_{0: 4}$ to $\mathrm{S}_{0: 6}$ & $\mathrm{CBD}^{1}-192$ plots & GH-dry 2013 & Resistance \\
\hline
\end{tabular}

${ }^{1} \mathrm{CBD}=$ Complete Block Design.

gressive isolate identified in the evaluation by Carneiro et al., (2011) was used.

The fungus was chopped up twice in Petri dishes containing potato dextrose agar (PDA) medium with chloramphenicol ( $1 \mu \mathrm{L} \mathrm{mL}^{-1}$ of PDA medium) and incubated at $22{ }^{\circ} \mathrm{C}$ for three days with a 12-hour photoperiod. Three days after the second multiplication, inoculations were performed by the straw test method. The method consists of cutting the stem apex around $2.5 \mathrm{~cm}$ above the node, where the tip of a $200 \mu \mathrm{L}$ micropipette is placed with a disc of the PDA culture medium containing the mycelium of $S$. sclerotiorum.

Seven days after inoculation, the reaction of common bean to white mold was evaluated by means of a diagrammatic scale from 1 (absence of symptoms) to 9 (rotting of at least 3 internodes or death of the plant) (Terán et al., 2006).

Growth habit was evaluated using a diagrammatic scale from 1 (plant type III - completely prostrate) to 9 (plant type I or II, upright, with one stem and high first pod height) according to Mendes et al. (2011). Grain type was evaluated using a diagrammatic scale from 1 (typical "Carioca" grain) to 5 (grain outside the "Carioca" standard) according to Ramalho et al. (2005).

\section{Statistical analyses}

As all the presuppositions of analysis of variance were accepted, the data of resistance to white mold, growth habit and grain type were subjected to analysis of variance. Analyses were carried out by generation $\left(\mathrm{S}_{0: 11^{\prime}}\right.$ $\mathrm{S}_{0: 2}$ and $\mathrm{S}_{0: 3}$ ) and sequential analysis of these generations by cycle, and all the effects of the model were considered as random, except for the mean.

For analysis of the experiments of the best progenies selected from each cycle carried out in the field and in the greenhouse the progenies were considered fixed.

The genetic variance $\left(\sigma_{P}^{2}\right)$, phenotypic variance $\left(\sigma_{F}^{2}\right)$, variance of the progeny ${ }^{*}$ generation interaction $\left(\sigma_{G^{*} P}^{2}\right)$ were estimated according to Ramalho et al., (2005); and heritability in the broad sense $\left(h^{2}\right)$, with its lower limits (LI) and upper limits (LS) according to Knapp et al. (1985); and selective accuracy $\left(\hat{r}_{\hat{g} g}\right)$ according to Resende and Duarte (2007). All analyses were performed using the software from SAS (Statistical Analysis System Institute, 2013).

Genetic progress was estimated using the mean values of the progenies obtained from the sequential analyses of cycles CIII, CIV, CV and CVI and using the mean values of the best progenies of seven cycles. The gain with progeny selection within cycles was also estimated. Progress estimates using experiments in different seasons and years were made using common controls for minimizing the environmental effect. Initially, genetic deviation of the mean values of the progenies was obtained in relation to the control for disease resistance, growth habit and grain type traits. In the estimate of genetic deviation for the resistance to white mold trait, the mean value of the "Corujinha" susceptible line was used; for grain type, the mean value of the "CNFC9506" line was used; and for growth habit, the mean value of these two lines. For the estimation of genetic progress, a linear regression equation was derived between the number of cycles as independent variable $(x)$, and the genetic deviation or the mean value of the progeny as dependent variable $(y)$. Genetic progress $(\mathrm{GP})$ percentage was obtained by the following estimator:

$G P=\left(\frac{b_{1}}{\bar{x}_{c i}}\right) * 100$

in which $b_{1}$ is the estimated linear coefficient or absolute gain and $\bar{X}_{c i}$ is the mean resistance in cycle three (CIII) in the evaluations considering all the progenies of each cycle (CIII, CIV, CV and CIV) and in cycle zero (CO) in the evaluations of the best progenies of each one of the seven cycles. 


\section{Results and discussion}

Evaluation of white mold resistance of progenies $\mathrm{S}_{0: 1}, \mathrm{~S}_{0: 2}$ and $\mathrm{S}_{0: 3}$

Experiments were carried out with good experimental precision, and the values of selective accuracy for the resistance to the white mold trait were greater than $66 \%$ in all experiments (Tables 3 and 4). This parameter refers to the correlation between the true genotypic value of the genetic treatment and that estimated or predicted from the information of the experiments (Resende and Duarte, 2007).

The analyses of variance, per generation or joint, showed differences $(p \leq 0.05)$ between the mean values of the progenies and between generations for severity of white mold, and the estimates of heritability in the joint analyses ranged from 60 to $86 \%$ (Table 3) with lower limits positive in all cycles. This suggests that the progenies with different levels of resistance have different favorable alleles and variability, which are essential to obtaining gain with selection.

There was no progeny ${ }^{*}$ generation interaction for three of the four cycles evaluated, and the ratio between variance of the interaction and genetic variance $\left(\sigma_{G^{*} P}^{2} / \sigma_{G}^{2}\right)$ * 100 was less than $22 \%$ in these three cycles (Table 3). This indicates that the behavior of the progenies was consistent over the generations, and that the selected progenies with a greater level of resistance in the $\mathrm{S}_{0: 1}$ generation of these cycles remained greater in the following generations, thus, indicating that selection in the $\mathrm{S}_{0: 1}$ gen-

Table 3 - Estimates of the mean square of progenies (MSP), mean square of error (MSE), selective accuracy ( $\hat{r}_{\hat{g} g}$ ), ratio between variance of the interaction and genetic variance $\left(\sigma_{G^{*} p}^{2} / \sigma_{G}^{2}\right)^{*} 100$, heritability $\left(h^{2}\right)$ and upper (UL) and lower (LL) limits of heritability of the progenies in cycles CIII, CIV, CV and CVI for common bean white mold resistance, growth habit and grain type.

\begin{tabular}{|c|c|c|c|c|c|c|c|}
\hline \multicolumn{8}{|c|}{ White mold resistance } \\
\hline Cycle & $\mathrm{MSP}^{1}$ & MSE & $\hat{r}_{\hat{g} g}$ & $\left(\sigma_{G X P}^{2} / \sigma_{G^{* P}}^{2}\right)^{*} 100$ & $h^{2}$ & $\mathrm{LL}$ & UL \\
\hline III & $1.060^{* *}$ & 0.368 & 81.78 & 2.624 & 64.720 & 51.09 & 74.16 \\
\hline IV & $2.095^{* *}$ & 0.248 & 93.91 & 7.151 & 86.110 & 82.21 & 89.04 \\
\hline V & $0.561^{* *}$ & 0.163 & 77.04 & 58.559 & 59.360 & 48.71 & 67.51 \\
\hline $\mathrm{VI}$ & $0.862^{* *}$ & 0.188 & 84.89 & 21.644 & 72.068 & 64.63 & 77.77 \\
\hline \multicolumn{8}{|c|}{ Growth habit } \\
\hline III & $1.627^{* *}$ & 0.548 & 73.23 & 44.44 & 87.95 & 86.94 & 93.10 \\
\hline IV & $1.051^{* *}$ & 0.593 & 58.99 & 62.09 & 35.11 & 16.91 & 48.77 \\
\hline V & $1.151^{\star *}$ & 0.495 & 63.93 & 52.96 & 47.22 & 33.44 & 57.83 \\
\hline$\underline{\mathrm{Vl}}$ & $1.191^{* *}$ & 0.476 & 71.65 & 52.38 & 49.87 & 36.53 & 60.10 \\
\hline \multicolumn{8}{|c|}{ Grain type } \\
\hline III & $1.387^{* *}$ & 0.093 & 96.60 & -1.30 & 94.38 & 92.19 & 95.89 \\
\hline IV & $0.489^{* *}$ & 0.100 & 83.61 & 22.27 & 73.21 & 65.67 & 78.87 \\
\hline V & $0.502^{* *}$ & 0.076 & 91.40 & 1.47 & 83.67 & 79.51 & 87.02 \\
\hline$\underline{\mathrm{Vl}}$ & $0.691^{* *}$ & 0.101 & 90.50 & 3.61 & 84.23 & 79.99 & 87.47 \\
\hline
\end{tabular}

${ }^{1 * *}$ significant at $1 \%$ probability level by the $\mathrm{F}$ test.

Table 4 - Mean resistance of the common bean progenies (CL) evaluated in generations $\mathrm{S}_{0: 1}, \mathrm{~S}_{0: 2}$ and $\mathrm{S}_{0: 3}$ in cycles III, IV, V and VI, mean of the susceptible control, Corujinha, genetic deviation (GD), genetic progress (GP), significance test (LSD) among the genetic deviations of the mean values of the generations within each cycle and the value of selective accuracy $\left(\hat{r}_{\hat{g} g}\right)$ in each generation.

\begin{tabular}{|c|c|c|c|c|c|c|c|}
\hline Cycle & Generation & Mean value of the progenies $\left(\mathrm{CL}^{1}\right)$ & Corujinha & GD & GP & Difference from GD of previous generations & $\hat{r}_{\hat{g} g}$ \\
\hline & $\mathrm{S}_{0: 1}$ & $4.02(2.54 / 5.55)$ & 5.04 & $1.01(2.5 /-0.51)$ & & & \\
\hline \multirow[t]{3}{*}{ III } & $\mathrm{S}_{0: 2}$ & $4.53(3.42 / 5.69)$ & 6.01 & $1.49(2.59 / 0.32)$ & 11.98 & $0.48^{* *}$ & 0.76 \\
\hline & $\mathrm{S}_{0: 3}$ & $3.51(2.88 / 4.81)$ & 4.81 & $1.29(1.93 / 0.00)$ & 3.50 & $0.28^{* *} .-0.20^{*}$ & 0.87 \\
\hline & $\mathrm{S}_{0: 1}$ & $4.69(3.20 / 6.15)$ & 5.73 & $1.04(2.57 /-0.42)$ & & & 0.76 \\
\hline \multirow[t]{3}{*}{ IV } & $\mathrm{S}_{0: 2}$ & $3.21(2.46 / 4.24)$ & 4.57 & $1.35(2.11 / 0.33)$ & 6.53 & $0.31^{* *}$ & 0.78 \\
\hline & $\mathrm{S}_{0: 3}$ & $3.60(2.6 / 4.53)$ & 5.02 & $1.42(2.42 / 0.49)$ & 4.05 & $0.38^{* *} \cdot 0.07^{\mathrm{ns}}$ & 0.87 \\
\hline & $\mathrm{S}_{0: 1}$ & $3.24(2.16 / 4.53)$ & 4.56 & $1.32(2.40 /-0.03)$ & & & 0.80 \\
\hline \multirow[t]{3}{*}{ V } & $\mathrm{S}_{0: 2}$ & $3.46(2.70 / 4.47)$ & 5.01 & $1.54(2.31 / 0.54)$ & 6.81 & $0.22^{* *}$ & 0.66 \\
\hline & $\mathrm{S}_{0: 3}$ & $2.87(2.11 / 3.81)$ & 4.29 & $1.42(2.18 / 0.48)$ & 1.50 & $0.10^{\text {ns }} \cdot-0.12^{\text {ns }}$ & 0.79 \\
\hline & $\mathrm{S}_{0: 1}$ & $3.46(2.41 / 5.20)$ & 4.74 & $1.27(2.33 /-0.46)$ & & & 0.96 \\
\hline \multirow[t]{3}{*}{ VI } & $\mathrm{S}_{0: 2}$ & $2.78(2.12 / 4.24)$ & 4.10 & $1.32(1.98 /-0.14)$ & 1.39 & $0.05^{\text {ns }}$ & 0.86 \\
\hline & $\mathrm{S}_{0: 3}^{0: 2}$ & $3.51(2.72 / 4.30)$ & 5.14 & $1.63(2.42 / 0.84)$ & 5.19 & $0.36^{* *} \cdot 0.31^{* *}$ & 0.92 \\
\hline & & & & & & & 0.71 \\
\hline
\end{tabular}

$\mathrm{CL}=$ confidence limit; **, ${ }^{*}$, significant at $1 \%$ and $5 \%$, respectively by the LSD test; $\mathrm{ns}=$ non-significant at $5 \%$ probability level by the LSD test. 
eration was already efficient. Nevertheless, for the CV cycle, there was a progeny * generation interaction, with a ratio $\left(\sigma_{P * G}^{2} / \sigma_{P}^{2}\right) * 100$ greater than $50 \%$ (Table 3). The interaction was accompanied by a small experimental error, which may explain its significance. Another factor that may explain the presence of the interaction is the sensitivity of the genotypes to environmental variations for the trait, especially variations related to moisture and temperature, just as observed by Miklas et al. (2013).

\section{Evaluation of white mold resistance of better prog- enies of each cycle}

In the experiments with the progenies selected from each cycle, there was a difference for the effects of cycles and progenies within cycles C0, CI, CIV, CV and CVI. This highlights the existence of genetic variability for the trait, even after the selection occurred over generations, which is of utmost importance to obtaining continual genetic progress from selection over generations and cycles.

There was also a difference between field experiments and greenhouse experiments, although no interactions between treatments within groups (represented by controls and progenies within cycles) and experiments (greenhouse and field) were observed. Nevertheless, there was interaction between cycles and locations. The difference between experiments and the interaction must have occurred due to differences in environmental conditions in the greenhouse and experimental fields; and the intensity of the disease in the greenhouse was greater than that in the field, where the temperature and moisture factors are more difficult to control. In spite of the presence of experiment $*$ cycle interaction, genetic correlation for the white mold resistance scores between the experiments performed in the greenhouse and in the field was relatively high, $80 \%$ and the best and worst progenies maintained their classifications in the two experiments.

\section{Gain with selection over generations within each} cycle

To verify if the selection within cycles was efficient, the gain realized from the selection was estimated. The great problem in the comparative evaluation of experiments performed in different cropping seasons and years is the environmental effect, and the use of controls can attenuate this effect. For severity of the pathogen, a susceptible cultivar has been used by different authors as an alternative to this problem (Amaro et al., 2007; Arantes et al., 2010).

Gain within the cycles was positive in all four cycles, but small in the three generations. This occurred mainly due to the reduction in genetic deviation from the $\mathrm{S}_{0: 2}$ to $\mathrm{S}_{0: 3}$ generation of cycles CIII and $\mathrm{CV}$, even though this reduction was not significant. The greatest gains in selection of progenies were observed from $\mathrm{S}_{0: 1}$ to $\mathrm{S}_{0: 2}$ in cycles CIII, CIV and CV, indicating greater selection efficiency in this generation (Table 4). The reason for these gains is that in the $\mathrm{S}_{0: 1}$ generation the selection was performed with larger populations, from 121 to 225 progenies, and this selection allowed us to eliminate progenies with higher susceptibility. There was a strong influence of the environment on the aggressiveness of the pathogen and, at various times, the mean score of aggressiveness increased (from $\mathrm{S}_{0: 1}$ to $\mathrm{S}_{0: 2}$ of cycles CIII and $\mathrm{CV}$, from $\mathrm{S}_{0: 2}$ to $\mathrm{S}_{0: 3}$ of cycles CIV and CVI), which would indicate reduction in resistance. Nevertheless, an increase in the mean score of the susceptible control was also observed, which resulted in an increase of genetic deviation, and the gain from selection became positive. This confirms the importance of the control in reduction of the environmental effect.

As for the confidence interval of the mean scores (Table 4), the lower limit consists of progenies with higher resistance levels, with values less than three, and genetic deviation (GD) greater than two in various situations. In addition, genetic variation of the upper limit of the mean scores increased from generation to generation within the four cycles, with the sole exception of $S_{0: 2}$ to $\mathrm{S}_{0: 3}$ of cycle CV. Thus, it was possible to eliminate the more susceptible progenies over the generations, which must have contributed to an increase in the gain. Precise evaluation allows an increase in the levels of resistance of the progenies and gain from selection.

The gain obtained from selection of progenies was less than that obtained by Terán and Singh (2009), who obtained a gain of around $20 \%$ in progeny selection. However, in this study, we selected progenies with white mold resistance and those progenies with grains far outside of the "Carioca" standard were eliminated, even if they exhibited greater levels of resistance. The selection was performed in the field, where environmental conditions are more difficult to control, while in a greenhouse, conditions more favorable to the development of the pathogen can be imposed and thus a greater discrimination of the progenies for selection can be achieved. Nevertheless, it should not be forgotten that evaluations in the field are important since they represent the real growing environment of the common bean. It is mainly required for plant architecture, which is an escape mechanism for the white mold since upright plants with more open canopy are less conducive to this disease (Soule et al., 2011).

\section{Genetic progress throughout the recurrent selection cycles for disease severity}

In a recurrent selection program, it is indispensable to evaluate the efficiency of the process periodically. For that reason, it is necessary to estimate the genetic progress (GP). Various strategies have been used for estimating genetic progress in autogamous species and, in this study, the following were performed: a comparison between cycles using the general mean value of the progenies of the cycle and a comparison between groups of progenies selected from each cycle in a single experiment, to exclude the effect of cropping seasons. 
In a comparison of the mean value of all the progenies of the different cycles, if the gain were calculated based on the direct mean value of the progenies, the gain would be $-8 \%$ per cycle. However, for reducing the environmental effect we use the genetic deviation, and the genetic progress estimated from this deviation was $4 \%$ per selection cycle (Figure 1). At first, this gain seems small; however, as three cycles per year were carried out, this gain becomes more pronounced, at $11 \%$ per year. It should be taken into consideration that for selection of the plants in $\mathrm{S}_{0}$ generation that were intercrossed for obtaining cycles, only the mean reaction of the two inoculations per plant were used.

The experiments with the progenies selected from each one of the seven cycles showed gains similar to those obtained in the evaluations with all the progenies obtained in each cycle and evaluated only in the field. In the evaluations of the progenies selected in the field, a gain of $3 \%$ per cycle was observed, and in the evaluations in a greenhouse $4 \%$; while in joint analysis, this gain was $4 \%$ (Figure 2).

The little genetic progress over the generations and throughout the cycles is due to the fact that the quantitative trait is being controlled by various genes of little and medium effect and also due to the effect of the environment on the expression of resistance. According to Miklas et al. (2013), 27 QTLs have already been identified for physiological resistance to white mold and 36 QTLs for traits related to escape mechanisms. If in the initial populations there are genes with greater effect, the gain expected in initial generations and cycles is greater, but if the genes involved are of little effect, the gain will be less, but progressive over the generations and cycles, as observed herein. In the

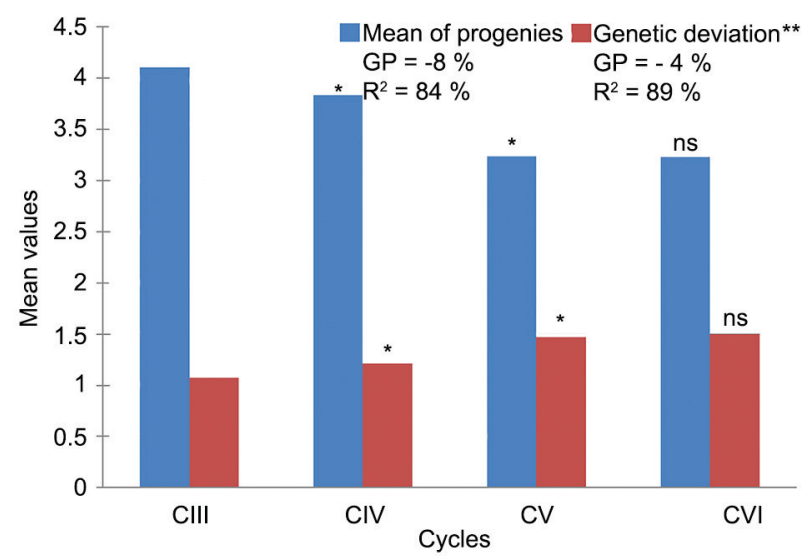

Figure 1 - Mean values obtained in each common bean cycle, genetic deviation (GD) and genetic progress (GP) for white mold severity. *Significant at $5 \%$ probability level by the LSD test; ns = non-significant at $5 \%$ probability level by the LSD test; Difference between mean values of previous cycle. ${ }^{\star *}$ Genetic deviation $=$ mean of control - mean of progenies. study of Lion et al. (1987) with the same pathogen, a gain of $31 \%$ was obtained after three cycles of recurrent selection; however, this gain was only possible because the authors performed interspecific crosses using a secondary gene pool where there are high levels of resistance. But in the studies of Terán and Singh (2010a) and Terán and Singh (2010b), evaluating two populations of double hybrids, the gains were less and similar to those obtained in this study.

Another important observation is that in the selection, adapted progenies were obtained with levels of resistance greater than that of non-adapted sources of resistance, such as Ex Rico 23(4.2 - 5.97), G122 (3.95 - 5), Cornell 605 (3.85 - 4.58), and A195 (3.48 - 4.21). Among these sources of resistance, A195 exhibited the lowest intensity of the disease. Considering joint analysis, it is noted that in cycles CIV, CV and CVI, progenies greater than A195 appeared. Terán and Singh et al. (2009) also obtained lines superior to the sources of resistance used as parents.

\section{Evaluation of growth habit and grain type}

Accuracy values were greater than $80 \%$ in the joint analyses for grain type and greater than $59 \%$ for growth habit, indicating good experimental precision in most of the experiments and a wide genetic variation among progenies. In consequence, the estimate of selection gain for growth habit was $5 \%$ per cycle $\left(\mathrm{R}^{2}=80 \%\right)$; this gain was possible because during the cycles, among the plants with greater levels of resistance, plants with better growth habit were prioritized for carrying out the intercrossing. For grain type there was no gain, because the selection was not performed

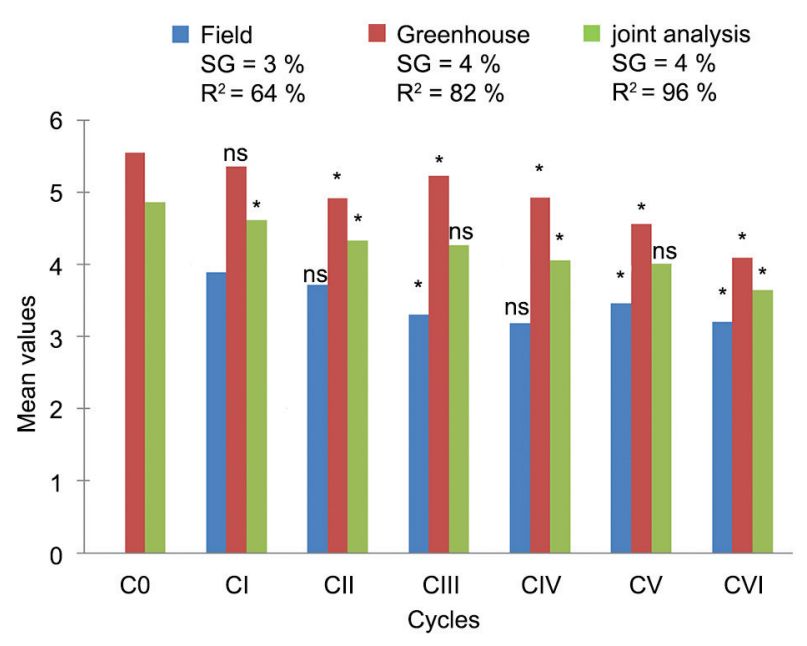

Figure 2 - Severity mean value of the progenies selected in each common bean cycle, and genetic progress in evaluations performed in the field, in the greenhouse and in joint analysis. *Significant at $5 \%$ probability level by the LSD test; ns = non-significant at $5 \%$ probability level by the LSD test; Difference between mean values of previous cycle for each experiment and for the joint analysis. 
for this trait in the base population to obtain the cycles. However, in the selection of progenies among generations within the cycles, there are progenies selected with mean values less or equal to the control (2.06), indicating there are progenies with acceptable grain under commercial conditions in all the generations of selection in the four cycles.

Evaluation of plant architecture in a recurrent selection program for white mold is of great importance since upright architecture, porous canopies, and resistance to lodging have much greater capacity for avoiding white mold disease (Miklas et al., 2013). These traits provide for unfavorable conditions for development of the pathogen. Lodged beans create denser and more compact canopies which result in cooler and more humid microclimates favorable to the pathogen. In addition, plant organs in contact with the ground are vulnerable to mycelia infections emanating from colonized senescent blossoms and leaf litter on the soil surface (Kolkman and Kelly, 2002; Kolkman and Kelly, 2003; Miklas et al., 2013). Physiological resistance in combination with disease avoidance traits did not require fungicide application to protect yield potential under moderate and heavy disease pressure (Miklas et al., 2013).

The importance of this trait is also evidenced in various studies of identification of QTL for resistance to white mold that mention the presence of those responsible for escape mechanisms, such as plant architecture, located together with the QTLs that confer resistance to white mold in beans (Miklas et al., 2013; Soule et al., 2011). Thus, it may be seen that selection for growth habit may contribute to resistance to white mold together with the physiological resistance identified by means of the straw test.

The 'Carioca' grain type is the most consumed in Brazil, and there are no cultivars with 'Carioca' grain and high levels of resistance to white mold adapted to Brazilian conditions, so the selection of these traits have been of great importance. Some Brazilian cultivars with 'Carioca' grains show certain levels of resistance, like those used in the base population of this study (Carneiro et al., 2011; Carvalho et al., 2013; Gonçalves and Santos, 2010; Silva et al., 2014), but these levels are still low, and compared with sources like G122 (3.95 - 5) and Ex rico $(4.2-5.97)$. In this study we noted that there are selected progenies with lower levels of resistance than A195 (3.48 - 4.21) and Cornell 605 (3.85 - 4.58). So we could increase these levels and obtain progenies with 'Carioca' grains and resistance similar and better than A195.

In light of the above, the selection of progenies with physiological resistance is of utmost importance, when these progenies accumulate desirable alleles of traits that contribute to resistance like erect growth habit and their grains satisfying the requirements of the consumer market. It is possible to reach these targets by recurrent selection since it makes it possible to recombine favorable alleles of the traits that are scattered in the parents.
Therefore, the procedure was efficient for obtaining progenies with a high level of resistance to white mold with "Carioca" grain type and upright growth habit. Furthermore, there is the possibility of achieving additional gains from the selection for resistance to white mold, growth habit and grain type due to the presence of genetic variability.

\section{Acknowledgements}

The authors thank the Brazilian National Council for Scientific and Technological Development (CNPq) and Coordination for the Improvement of Higher Level Personnel (CAPES).

\section{References}

Amaro, G.B.; Abreu, A.F.B.; Ramalho, M.A.P.; Silva, F.B. 2007. Phenotypic recurrent selection in the common bean (Phaseolus vulgaris $\mathrm{L}$ ) with carioca-type grains for resistance to the fungi Phaeoisariopsis griseola. Genetics and Molecular Biology 30: 584-588.

Arantes, L.O.; Abreu, A.F.B.; Ramalho, M.A.P. 2010. Eight cycles of recurrent selection for resistance to angular leaf spot in common bean. Crop Breeding and Applied Biotechnology 10: 232-237.

Carneiro, F.F.; Santos, J.B.; Gonçalves, P.R.C.; Antonio, R.P.; Souza, T.P. 2011. Genetics of common bean resistance to white mold. Crop Breeding and Applied Biotechnology 11: 165-173.

Carvalho, R.S.B.; Lima, I.A.; Alves, F.C.; Santos, J.B. 2013. Selection of carioca common bean progenies resistant to white mold. Crop Breeding and Applied Biotechnology 13: 172-177.

Ender, M.; Kelly, J.D. 2005. Identification of QTL associated with white mold resistance in common bean. Crop Science 45: 24822490.

Gonçalves, P.R.C.; Santos, J.B. 2010. Physiological resistance of common bean cultivars and Lines to white mold based on oxalic acid reaction. Annual Report of the Bean Improvement Cooperative 53: 236-237.

Knapp, S.J.; Stroup, W.W.; Ross, W.M. 1985. Exact confidence intervals for heritability on a progeny mean basis. Crop Science 25: 192-194.

Kolkman, J.M.; Kelly, J.D. 2002. Agronomic traits affecting resistance to white mold in common bean. Crop Science 40: 281-285.

Kolkman, J.M.; Kelly, J.D. 2003. QTL conferring resistance and avoidance to white mold in common bean. Crop Science 43: 539-548.

Lara, L.A.C.; Santos, J.B.; Veloso, J.S.; Balestre, M.; Alves, F.C.; Leite, M.E. 2014. Identification of QTLs for resistance to Sclerotinia sclerotiorum in carioca common bean by the Moving Away method. ISRN Molecular Biology. 2014: Article ID 828102. http://dx.doi.org/10.1155/2014/828102.

Lyon, M.E.; Dickson, M.H.; Hunter, J.E. 1987. Recurrent selection for resistance to white mold in Phaseolus species. Journal of the American Society for Horticultural Science 112: 149-152. 
Mendes, F.F.; Ramalho, M.A.P.; Abreu, Â.F.B. 2011. Nine-hole system efficiency in selection of carioca-type common bean progenies for erect architecture. Pesquisa Agropecuária Brasileira 46: 1029-1034 (in Portuguese, with abstract in English).

Miklas, P.N.; Grafton, K.F.; Hauf, D.C.; Kelly, J.D. 2006. Registration of partial white mold resistant pinto bean germplasm line USPT-WM-1. Crop Science 46: 2339.

Miklas, P.N.; Porter, L.D.; Kelly, J.D.; Myers, J.R. 2013. Characterization of white mold disease avoidance in common bean. European Journal of Plant Pathology 135: 525-543.

Mkwaila, W.; Terpstra, K.A.; Ender, M.; Kelly, J.D. 2011. Identification of QTL for agronomic traits and resistance to white mold in wild and landrace germplasm of common bean. Plant Breeding 130: 665-672.

Ramalho, M.A.P.; Abreu, A.F.B.; Santos, J.B. 2005. Genetic progress after four cycles of recurrent selection for yield and grain traits in common bean. Euphytica 144: 23-29.

Rangel, R.M.; Amaral, A.T.; Scapim, C.A.; Freitas Jr., S.P.; Pereira, M.G. 2008. Genetic parameters in parents and hybrids of circulant diallel in popcorn. Genetics and Molecular Research 7: 1020-1030.

Resende, M.D.V.; Duarte, J.B. 2007. Precision and quality control in Variety trials. Pesquisa Agropecuária Tropical 37: 182-194 (in Portuguese, with abstract in English).

Saharan, G.S.; Mehta, N. 2008. Sclerotinia Diseases of Crop Plants: Biology, Ecology and Disease Management. LXII. Springer, Heidelberg, Germany.

Schwartz, H.F.; Singh, S.P. 2013. Breeding common bean for resistance to diseases: a review. Crop Science 53: 1832-1844.

Silva, P.H.; Santos, J.B.; Lima, I.A.; Alves, F.C.; Lara, L.A. 2014. Reaction of common bean lines and aggressiveness of Sclerotinia sclerotiorum isolates. Genetic and Molecular Research 13: 91389151.
Singh, S.P.; Terán, H.; Schwartz, H.F.; Otto, K. Lema, M. 2009a Development of white mold resistant interspecific common bean germplasm lines VCW 54 and VCW 5. Journal of Plant Registrations 3: 191-197.

Singh, S.P.; Terán, H.; Schwartz, H.F.; Otto, K.; Lema, M. 2009b. Introgressing white mold resistance from Phaseolus species of the secondary gene pool into common bean. Crop Science 49: 1629-1637.

Soule, M.; Porter, L.; Medina, J.; Santana, G.P.; Blair, M.W. Miklas, P.N. 2011. Comparative QTL map for white mold resistance in common bean, and characterization of partial resistance in dry bean lines VA19 and 19365-31. Crop Science 51: 123-139.

Terán, H.; Lema, M.; Schwart, H.F.; Duncan, R.; Gilbertson, R.; Singh, S.P. 2006. Modified Petzoldt and Dickson scale for white mold rating of common bean. Annual Report of the Bean Improvement Cooperative 49: 115-116.

Terán, H.; Singh, P.S. 2008. One cycle of recurrent selection for physiological resistance to white mold in dry bean. Annual Report of the Bean Improvement Cooperative 51: 42-43.

Terán, H.; Singh, S.P. 2009. Gamete selection for improving physiological resistance to white mold in common bean Euphytica 167: 271-280.

Terán, H.; Singh, S.P. 2010a. Recurrent selection for physiological resistance to white mold in dry bean. Plant Breeding 129: 327333.

Terán, H.; Singh, S.P. 2010b. Gamete and recurrent selection for improving physiological resistance to white mold in common bean. Canadian Journal of Plant Science 90: 153-162. 